\title{
Experience in the restoration of permafrost degradation areas adjacent to transport infrastructure facilities
}

\author{
Nahapet Ustyan ${ }^{1, *}$ \\ ${ }^{1}$ GEO-PROJECT LLC, Saint-Petersburg, 195220, Russia
}

\begin{abstract}
The construction of transport facilities in the regions of the Extreme (or Far) North and the Arctic Zone is a very specific task with plenty of peculiarities. This can be referred to ever-frozen subsoils, hard-toreach areas, low temperatures most of the year, as well as limited reserves of inert materials (stone, construction sand) used for construction.
\end{abstract}

\section{Introduction}

Local loamy soils containing ice are used in the construction of roadbeds for highways and railways. They have relatively high degree of subsidence, as well as lose its bearing capacity and become fluid in a melting time, leading to sufficient deformations of roadbeds, clogging of culverts and ditches. Moreover, an adjacent territory requires much attention as the source of basic danger for roads. The danger means, that the process of a frozen base degradation of the adjacent territory can be quickly transferred to the roadbed. It can start from an adjacent lake, a small stream, a ditch and other source and quickly expand towards the road. In some cases, it is not only local degradation of a frozen soil, but a solid wash-out of smooth slopes caused by imbalance of shear pressures (Fig.1).

Generally, the degradation of permafrost started from ditches along the embankment or from unfortified channels of culverts on the slopes. They are intensively washed-out under the water flow that has not been here before. Such cases also occurred during the construction and further operation of the Obskaya-Bovanenkovo railway line, where the witness and coordinator of relieving the consequences was the author of this article. It definitely caused a great damage, as well as could have other catastrophic consequences with the closure of the road and reconstruction of entire sections along the new center line. Only emergency actions taken to liquidate such damages and the source of degradation helped to save the road from imminent destruction.

\footnotetext{
*Corresponding author: nagapet_ustyan@mail.ru
} 


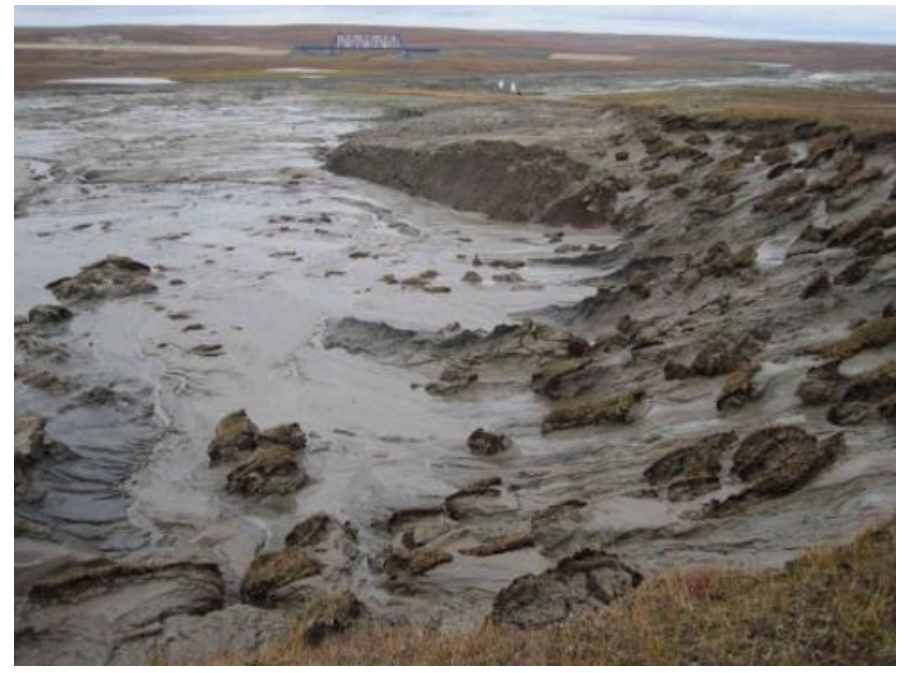

Fig.1. Wash-out of a road adjacent to the railway.

\section{Results}

One of the most striking examples of degradation of the adjacent territory with a real threat to the integrity of the functional railway track occurred in August 2013 at the $536^{\text {th }} \mathrm{km}$ of the Obskaya-Bovanenkovo railway line. The work was completed 3 years ago, and the road was in service. The site was a cut up to 2 meters deep, where the permafrost layer was broken during the construction, as well as on the slope of the cut. After filling the embankment, the slope was covered with $50 \mathrm{~cm}$ thick local soil and strengthened by geotextiles with grass seeds. But the grass practically did not grow because of the cold weather and lack of feeding. The slope in winter is full of snow, and in spring a warm melting water washed-out this local soil from under the slope reinforcement, forming deep wash holes and completely clogging a catch-water ditch along the embankment. Finally, water began to flow through the body of the embankment towards the lake, bulging out (or lifting up) the slope, as well as soaking into the soil of the active layer along the embankment and rapidly breaking it out. The runlet appeared from the empanelment side, flowing into the lake along the slope and washing away the permafrost of the bank. During one of the hottest days of August (temperature was up to $+33^{\circ} \mathrm{C}$ ) such melting water passed upstream and started to actively expand the channel under the intensive sun. Within three days the area of degradation reached approximately $50 \mathrm{~m}$ in length and $30 \mathrm{~m}$ in width. Next evening by the time of our arrival to the site, there has already been a great wash up to $100 \mathrm{~m}$ in length, $52 \mathrm{~m}$ in width and up to $4 \mathrm{~m}$ in depth. The table soil flowed into the lake, and it was only $10 \mathrm{~m}$ from the railway (Fig. 2). The inspection of the site proved that it would be difficult to immediately stop such degradation and close the site due to the lack of resources. Thus, it was decided to divide this into stages. Urgent measures have been taken to prevent from further melting towards the railway. It was necessary to stop melting process towards the road at the first stage, and then close the bottom and walls of the wash, not allowing further degradation development. First thing to do was the substitution of the running soil by the rocky soil using geotextile for the length of a dangerous site. 


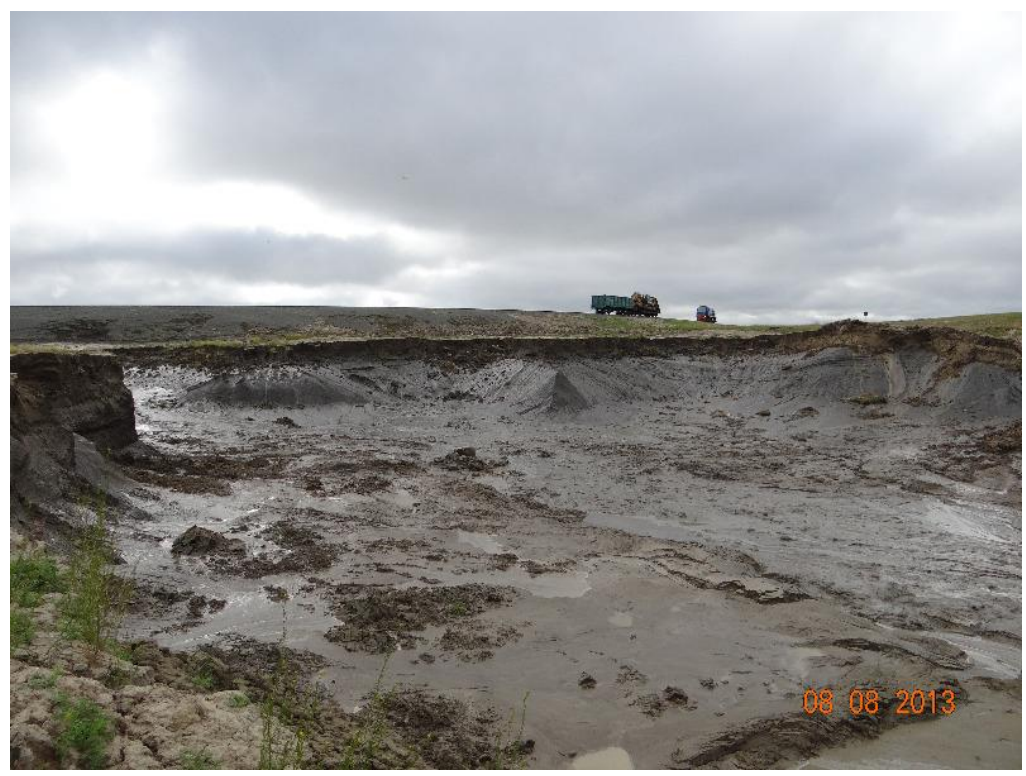

Fig. 2. Degradation of the adjacent railway territory.

This allowed saving the embankment and part of the soil along the slope with a simultaneous filling of the washed edge. At the same time, we started to clear a catch water ditch to separate (or cut off) a water flow into the embankment. The rest part of the site was covered by geotextile till the next delivery of the rocky soil and further decision-making. Later on, a project for restoration of this site was developed within 24 hours. It consisted of 2 steps. The first step included filling and restoration of the cut slope, as well as reconstruction of the ditch along the slope, and the second one included liquidation of the washed area adjacent to the railway line. But due to the lack of resources, we managed to perform only the most urgent measures suspending the melting of permafrost and flowing of the running soil into the lake. Moreover, the temperature on the next day dropped to $+12^{\circ} \mathrm{C}$, the cold wind blew, significantly slowing down the melting process. During that day it was possible to expand the filling line of the washed area up to $5 \mathrm{~m}$, cover the bottom with geotextile and partially fill with the rocky soil. The work on liquidation of the washed area has been stopped due to the lack of soil and geotextile, avoiding the risk of full destruction of the railway road. While surveying the site, our group has left for the development of a proper comprehensive project on restoration of the degradation area (Fig. 3).

The project was developed in a short period of time and sent to the railway administration of the Obskaya-Bovanenkovo line. This project was used for further liquidation of consequences due to the melting of permafrost, as well as reinforcement of the slope. Within one year the site was restored (Fig. 4), and currently is in a stable condition.

But there are questions remained that are very important and relevant for any road that is built on permafrost soils. How to avoid such troubles and what is to be done to timely liquidate the consequences of degradation?

These issues are especially important for new roads, where a number of processes on an adaptation of the road and the environment take place. The experience of construction and operation, as well as performed observations, show that the overwhelming majority of sudden degradation of the adjacent territory takes place during the first 5-7 years of road functioning, then there are "chronically sick" places remained that can't be stabilized for a long time. 


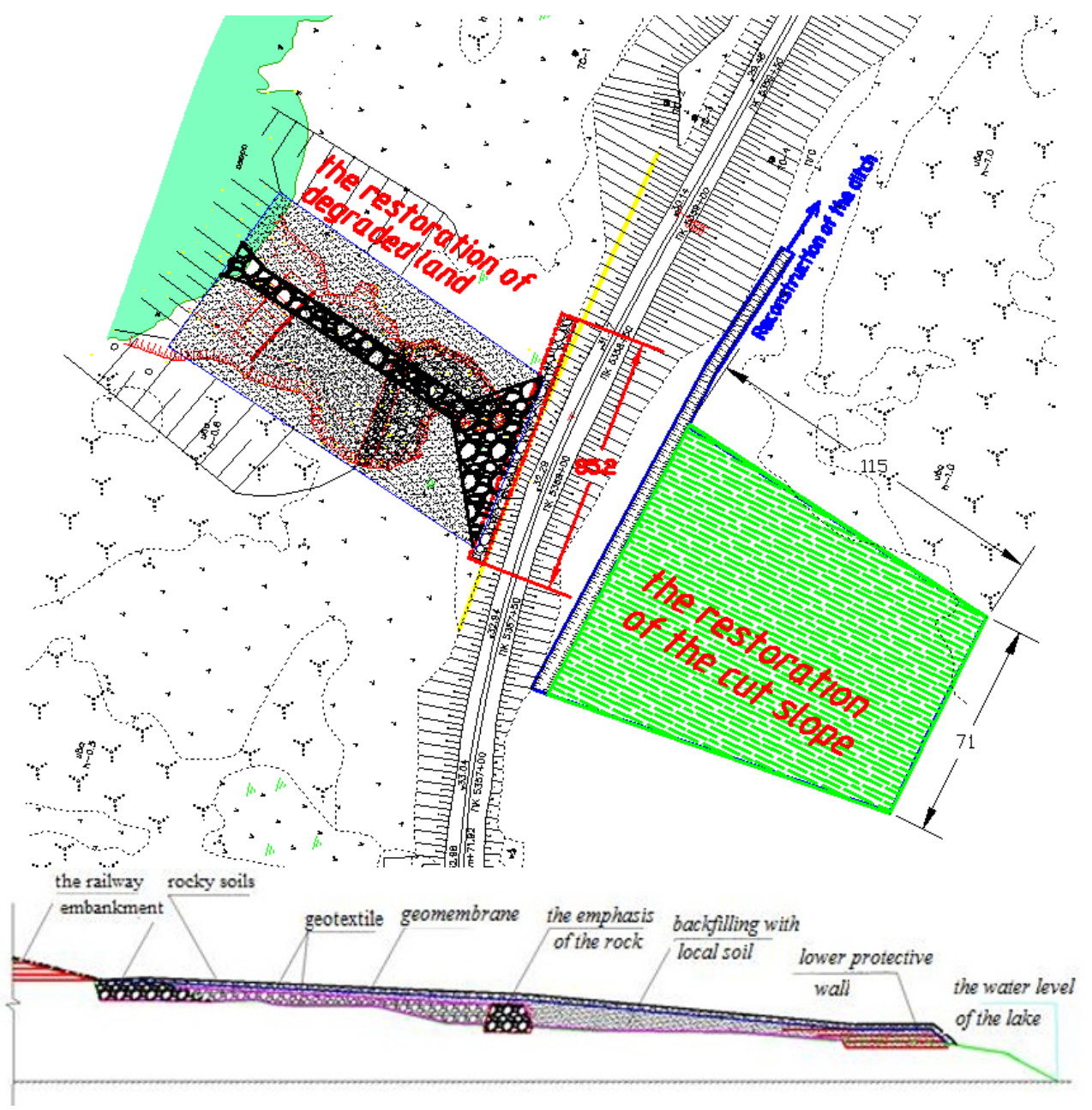

Fig. 3. Plan and cross-section of the project for restoration of the degradation area.

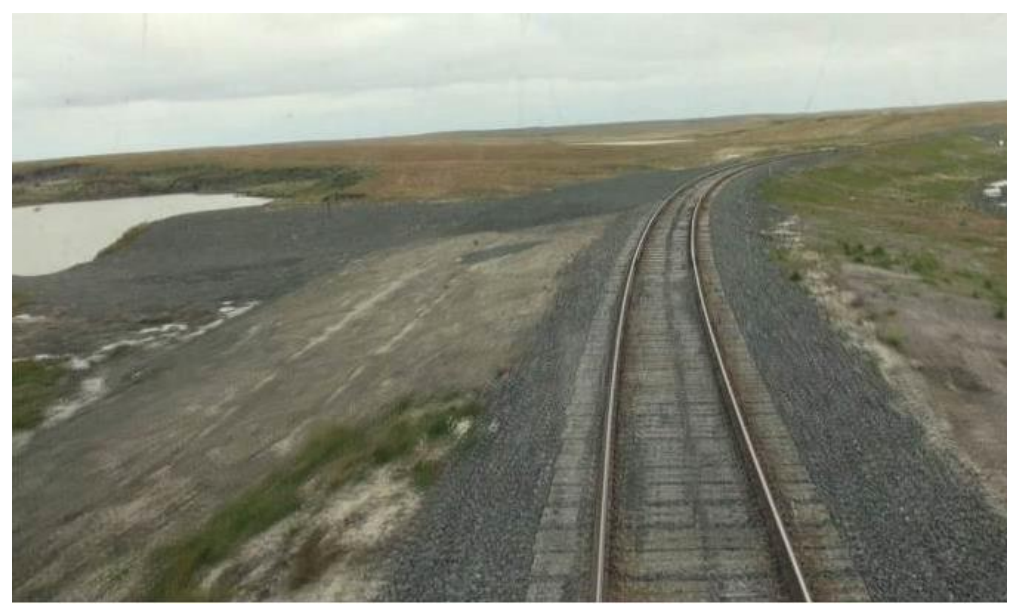

Fig. 4. The site after restoration (2015). 
These places are usually known, and they are constantly monitored, so the risks of sudden deformations of the site are small. What are the causes of these sudden permafrost degradations of an adjacent territory?

Its number is significant, but the main causes are:

- the low quality of conducting surveys, where the issues of permafrost condition of adjacent territories are not considered;

- outdated regulatory framework (ISCS (Industry-Specific Construction Standards) 61-89, ISCS 84-89) on the highway and railway design;

- $\quad$ poor design quality, not considering the impact of the adjacent territory on the integrity of roadbeds;

- lack of reinforcements of water channels on the slopes from pipes up to culverts;

- correct reinforcement of the slopes and cuts;

- mistakes and deliberate changes of design solutions on the part of builders during project implementation;

- lack of or limited geotechnical monitoring of the soil and constructed facilities;

- administration disregard of recommendations from scientific and project organizations, as well as monitoring results and etc.

We can list causes for a long time, but what is to be done when the facts of degradation have already occurred? In this regard at the very beginning, these issues should be thought over beforehand, and the measures for the liquidation of emergency situations should be worked out. In particular, the following should be also considered:

- creation of the emergency reserve of materials at the stations for restoration with a view to 4 hauls in the following volumes: - 4-5 thousand $\mathrm{m} 3$ of rocky soils, 3-4 thousand $\mathrm{m} 2$ of geotextile, 1-2 thousand $\mathrm{m} 2$ of geomembrane;

- creation of emergency train at each road distance with a qualified staff, including locomotive, 4-6 dumping wagons (or dump cars), accommodation/living wagon (car), excavator, bulldozer, loader and other equipment for an immediate drive to the damaged site, if necessary;

- well-trained personnel having skills to restore permafrost roads.

\section{Conclusions}

Summarizing all the above said, it should be noted that the warming significantly affects the melting of permafrost soils in the Extreme North regions, thus the risk of emergency situations becomes higher. Timely measures taken to prevent accidents and readiness to liquidate the consequences can save such complex roads in permafrost regions.

\section{References}

1. ISCS 61-89. Survey, design and construction of railways in permafrost regions (The Ministry of transport construction USSR, Moscow, 1990)

2. ISCS 84-89. Survey, design and construction of highways in permafrost regions (The Ministry of transport construction USSR, Moscow, 1990)

3. The project design on the restoration of the damaged site at the 536th $\mathrm{km}$ of the "Obskaya-Bovanenkovo" railway line, Report of the «Yamal» Engineering centre (2013)

4. Highway and railway construction in permafrost regions, Scientific papers of OJSC (Central Scientific Research Center of Construction, Moscow, 2007) 